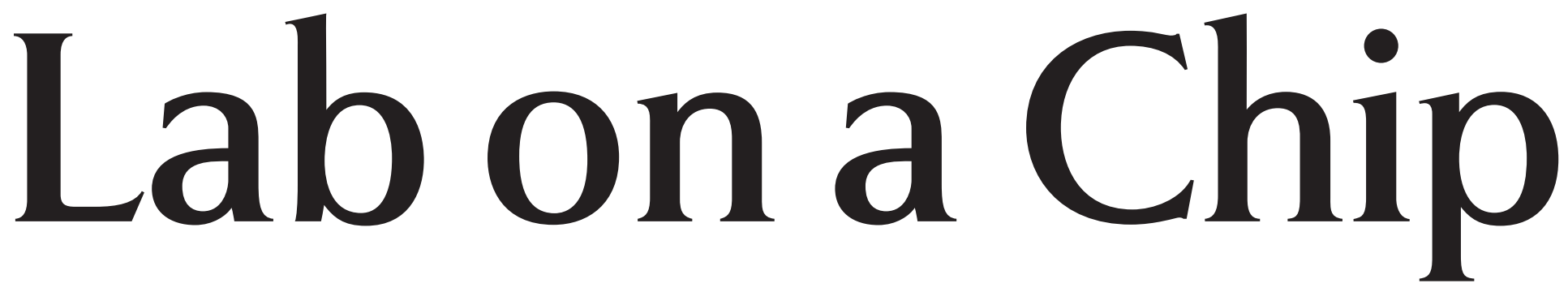

Miniaturisation for chemistry, biology \& bioengineering

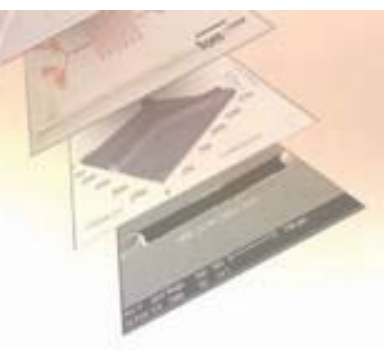




\title{
Novel inorganic polymer derived microreactors for organic microchemistry applications
}

\author{
Tae-Ho Yoon, ${ }^{a}$ Sang-Hee Park, ${ }^{a}$ Kyoung-Ik Min, ${ }^{a}$ Xunli Zhang, ${ }^{b}$ Stephen J. Haswell ${ }^{c}$ and Dong-Pyo Kim*a,d
}

\author{
Received 19th March 2008, Accepted 19th June 2008 \\ First published as an Advance Article on the web 15th July 2008 \\ DOI: $10.1039 / b 804726 j$
}

Microreactors fabricated with optically transparent inorganic polymers from two types of precursors using a UV-microimprinting process demonstrated reliable solvent resistance and capability for performing three model organic synthetic reactions, which were compared with batch systems and glass based microreactors.

\section{Introduction}

During the last two decades, significant development in the fields of miniaturized systems, so-called microfluidics or labon-a-chip technologies, has been achieved and spread widely over diverse areas such as bioengineering, optics and electronics. One of the main driving forces behind such work is the unique characteristics of microreactors, compared with that of conventional reaction vessels, including a high surface-to-volume ratio, diffusion dominated mass transfer, and the capability for spatial and temporal control of reaction reagents and products. ${ }^{1,2}$ In particular, the high surface-to-volume ratio is beneficial for heat transfer enhancement allowing one to utilize the full potential of catalysts during highly endothermic or exothermic reaction while avoiding formation of high thermal gradients. ${ }^{3}$ In addition, the small dimensions of the reactor channel ensure a short radial diffusion time leading to a narrow residence time distribution. ${ }^{4}$ This is advantageous for consecutive processes since high selectivity to the desired intermediate can be achieved.

Currently, a wide variety of materials, including metal, silicon, glass and polymers, have been used to fabricate microfluidic devices, such as microchips or microreactors. ${ }^{5}$ Silicon has been used widely in the field of MEMS applications by means of a semiconductor process with high manufacture costs using dry and wet etching. In the meantime, polymers such as PDMS and PMMA have been widely used in a range of microfluidic systems owing to their convenient and cheap process based on soft lithography techniques. However, the properties of these polymers, including low mechanical strength and poor solvent resistance against most non-aqueous solutions, restrict their applications in particular for organic reaction systems. Thus, there has been an increasing need to develop novel materials with reliable durability for the fabrication of microfluidic devices by adopting the well-developed facile fabrication process, leading to

\footnotetext{
${ }^{a}$ Department of Finechemical Engineering, Chungnam National University, Daejeon, 305-764, South Korea

${ }^{b}$ Bioengineering Group, School of Engineering Sciences, University of Southampton, Southampton, SO17 1BJ, UK

'Department of Chemistry, The University of Hull, Hull, HU6 7RX, UK ${ }^{d}$ Center for Ultramicrochemical Process Systems (CUPS), KAIST, 305-701, South Korea
}

potential replacement of current glass or metal based microfluidic devices for versatile applications. We have recently reported the development of polyvinylsilazane inorganic polymer and the feasibility for the fabrication of glass-like microchannels and substrates using a simple and cost effective UV-microimprinting process which is followed by a sequential photocuring and thermal cross-linking step. ${ }^{6,7}$ It has been demonstrated that such cured polyvinylsilazane exhibits high optical transparency and organic solvent resistance.

In this paper, we report further the development of microreactors using two types of commercially available inorganic polymers, namely polyvinylsilazane and allylhydropolycarbosilane, based on a micro-imprinting lithography fabrication technique, and their applications for organic synthesis. Three model organic chemical reactions have been selected; synthesis of 3,5-dimethylpirazole, exothermic Diels-Alder cyclo-addition and Knovenagel reaction, which are carried out in commonly used organic solvents including THF, acetonitrile and DMF. It is believed that, to our knowledge, this is the first attempt to demonstrate these organic reactions within polymer-based microreactors. The microchemical performance of two inorganic polymer microchannels is preliminarily evaluated in comparison to those of glass-based microreactors and batch reaction systems. The results indicate that the novel inorganic polymer-based microreactors can provide an economic and versatile platform for both aqueous and non-aqueous chemistry applications.

\section{Materials and methods}

The microreactor was fabricated by UV-imprinting techniques with PDMS (polydimethylsiloxane, Sylgard 184, Dow Corning, USA) replica molds which were prepared using the conventional soft lithography method with silicon wafer fabricated with SU-8 photoresist (Microchem, USA) as reported in the literature. ${ }^{8}$ To fabricate the microreactor, allylhydridopolycarbosilane (AHPCS, SMP-10 ${ }^{\circledR}$, Starfire systems, USA) and polyvinylsilazane (PVSZ, KION VL-20 ${ }^{\circledR}$, Clarient, USA) (Fig. 1) with low viscosity were used directly or with dilution using tetrahydrofuran (THF, Sigma-Aldrich, USA), depending on the coating thickness. In addition, $2 \mathrm{wt} \%$ of dicumylperoxide (SigmaAldrich, USA) and Irgacure 500 (Ciba Specialty, Japan) as a thermal and a photo initiator, respectively, were mixed into the 


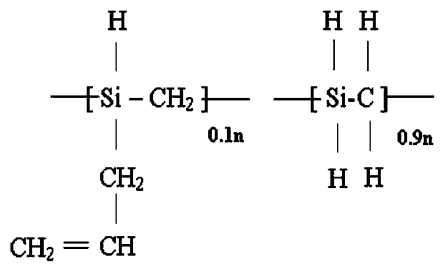

(a)

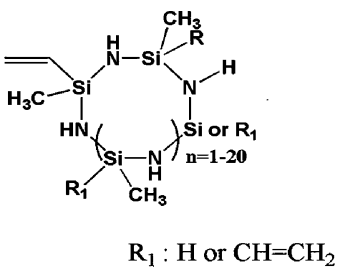

(b)
Fig. 1 Polymeric structures of (a) allylhydridopolycarbosilane (AHPCS) and (b) polyvinylsilazane (PVSZ).

inorganic polymers. The solvent resistance of the cured AHPCS was investigated by the identical method as reported for cured PVSZ. ${ }^{6,9}$ The samples were prepared in the PDMS cast with $1 \times$ $1 \mathrm{~cm}$ (width $\times$ length) and $1 \mathrm{~mm}$ of thickness and soaked in the diverse solvents for $24 \mathrm{~h}$. Finally, the swelling ratio, $D / D_{\mathrm{o}}$, where $D$ and $D_{\text {o }}$ are the lateral width of sample in solvent for $24 \mathrm{~h}$ and that of the dried sample, respectively, was examined. For the optical transmittance with the UV-VIS spectrophotometer (Avantes, Netherland), the inorganic polymer films with $\sim 10 \mu \mathrm{m}$ spun-coated on glass slides and cured at $100-160{ }^{\circ} \mathrm{C}$ in nitrogen atmosphere were used. In addition, PDMS films having the same thickness were prepared as a reference sample. The fabrication processes of the inorganic polymer derived microchannel was illustrated in Fig. 2. To prevent the unwanted adhesion between stamps and inorganic polymers, a mold release agent (Kion mold release, Clariant, USA), diluted with hexane, was spincoated on the PDMS stamp at a spin rate of $2000 \mathrm{rpm}$ for $30 \mathrm{~s}$, which was then baked at $70{ }^{\circ} \mathrm{C}$ for $5 \mathrm{~h}$ and ready for use. Microchannels were created by placing the stamp with relief structures (typically $50 \mu \mathrm{m}$ high and $380 \sim 500 \mu \mathrm{m}$ wide) on the viscous inorganic polymer layer which was formed by dropping the liquid inorganic polymer on a pre-cleaned glass slide under nitrogen atmosphere. Subjected to a UV exposure (ELC-4100 UV light system) for $20 \mathrm{~min}$ the liquid inorganic

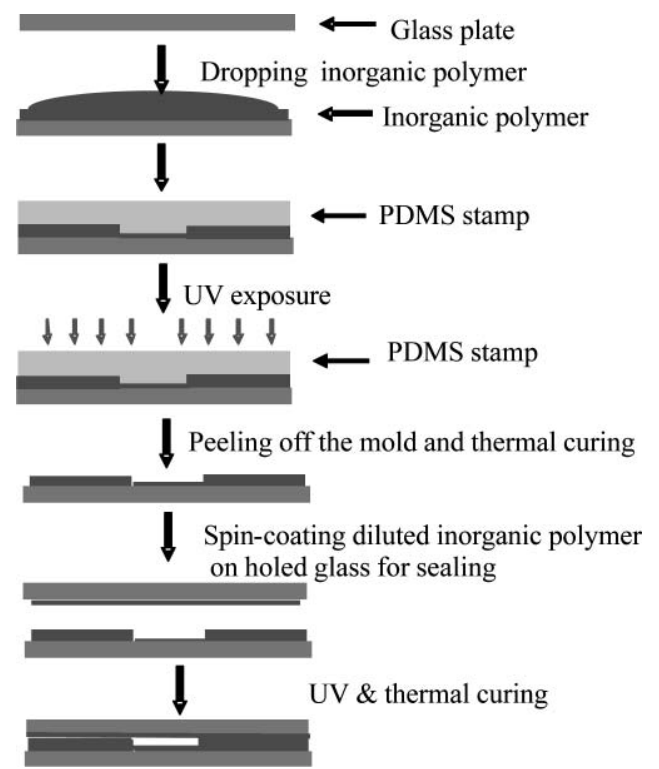

Fig. 2 Schematic fabrication process of inorganic polymer derived microchannel between glass slides. polymer was cured and solidified. After peeling off the PDMS stamp, the patterned microchannel was thermally post-cured for $3 \mathrm{~h}$ at either $160^{\circ} \mathrm{C}$ for AHPCS (polyallylhydridocarbosilane), or $150^{\circ} \mathrm{C}$ for PVSZ (polyvinylsilazane) at a heating and cooling rate of $2.5{ }^{\circ} \mathrm{C} \mathrm{min}^{-1}$ under nitrogen atmosphere. To close the microchannel using the same material, a thin polymer film (3$4 \mu \mathrm{m})$ was spin-coated on a top glass slide which was then gently placed on the patterned structure. A sequential UV exposure and thermal curing under the identical conditions described above resulted in an irreversible sealing of the microchannel. The holes (diameter $1.5 \mathrm{~mm}$ ) on either side of the supporting bare glass slides were mechanically drilled through to connect the microchannel with tubing. Thus, a microreactor with microchannels (typical dimensions: $500 \mu \mathrm{m}$ wide, $50 \mu \mathrm{m}$ deep, $2-16 \mathrm{~cm}$ long) within an inorganic polymer layer which was sandwiched between two glass slides was fabricated. The microreactors were then connected to pumping devices via PFPE tubes (1/16" OD, Upchurch, USA). To secure the connection between the holes on the supporting glass and the tube, a ceramic sealing (Torrseal, USA) material was used. The morphology or topography of the fabricated microchannel was determined by SEM (FE-SEM, XL30SFEG, Philips, Netherland, 5 kV) and a digital imaging technique (AQM image acquisition software). ${ }^{10}$

In order to evaluate the performance of the inorganic polymer derived microreactors, three organic synthetic reactions (Fig. 3) were carried out, namely, synthesis of 3,5-dimethylpirazole, exothermic Diels-Alder cyclo-additions and Knovenagel condensation, under different reaction conditions. ${ }^{11,12}$ All chemicals used were purchased from Sigma-Aldrich and used without additional purification. All liquid samples were pressure-driven into the channel using syringe pumps (KDS 100, KD Scientific Inc., Holliston, MA, USA) at flow rates in the range 0.67$60 \mu 1 \mathrm{~min}^{-1}$. The quantitative analysis of products was performed with a GC-MS (Gas chromatography-mass analyzer, Varian GC (CP-3800) coupled to a Varian MS (2000), USA), capillary column (DB-35MS, $0.25 \mu \mathrm{m} \times 30 \mathrm{~m} \times 0.32 \mathrm{~mm}$ ) and a GC-FID (Shimadzu, GC 17A, Japan, capillary column $30 \mathrm{~m}$, Zebron ZB 5, Phenomenex, USA). Fig. 3 shows the three reaction schemes. During the reaction of 3,5-dimethylpirazole synthesis, $0.1 \mathrm{M}$ acetylacetone in THF solution, and $0.1 \mathrm{M}$ hydrazine monohydrate in THF solution, were introduced into the $\mathrm{Y}$ shaped channel at an equal flow rate ranging from 0.76 to $10 \mu 1 \mathrm{~min}^{-1}$ (Fig. 3(a)). For comparison, this reaction was run within a glass made microreactor having identical channel design and dimensions. It was also carried out in a batch format using a glass vial. ${ }^{11-13}$ The catalyzed Diels-Alder cycloaddition was performed by flowing in a mixture of $1 \mathrm{mM}$ of ethylacrylate and 2,3-dimethyl-1,3-butadiene with THF via one inlet of the $\mathrm{Y}$ shaped channel, and a solution of $2.5 \mathrm{~mol} \%$ of $\mathrm{AlCl}_{3}$ in THF via the other inlet (Fig. 3(b)), whilst the temperature of the microreactor was kept constant at $45^{\circ} \mathrm{C}$ using a hotplate (Fisher Scientific, USA). The Knovenagel reaction (Fig. 3(c)) was carried out within an extended Y channel allowing a longer residence time for reaction where ethyl cyanoacetate mixed with piperazine (v/v, $10: 1)$ in THF was introduced from one inlet and the benzaldehyde solution from the other. This was also compared with batch reaction results. 
(a)

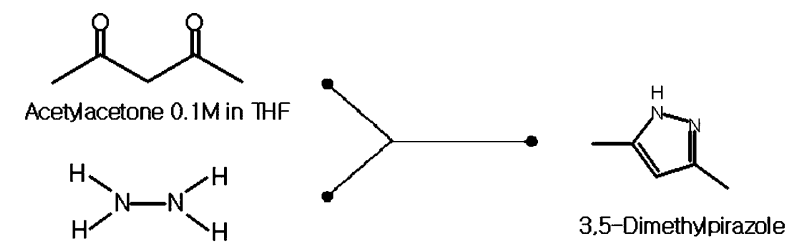

Hydrazine anhydrous $0.1 \mathrm{M}$ in THF

(b)

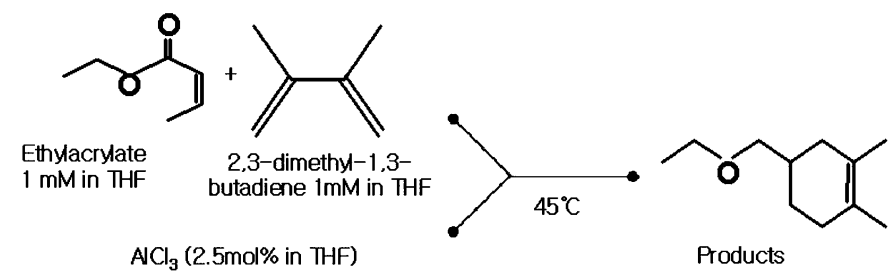

(c)

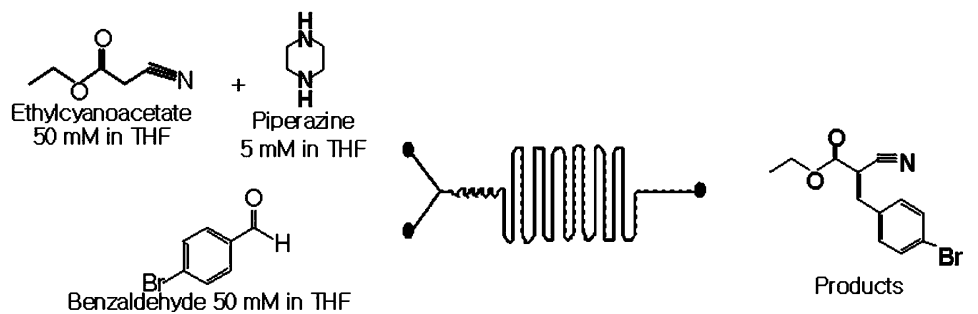

Fig. 3 Reaction schemes for (a) synthesis of 3,5-dimethylpirazole, (b) Diels-Alder cycloaddition and (c) Knovenagel reaction.

\section{Results and discussion}

\section{Solvent resistance and optical transparency}

Solvent resistance of the structural material used is an essential characteristics for developing microfluidic devices applicable for non-aqueous as well as aqueous mediums. This has been examined with a range of solvents including water and different solvents. Table 1 summarises the results with AHPCS samples cured for $3 \mathrm{~h}$ at two temperature levels of $100^{\circ} \mathrm{C}$ and $160{ }^{\circ} \mathrm{C}$. It was observed that temperature had significant effects on the solvent resistance performance; samples cured at $100{ }^{\circ} \mathrm{C}$ showed

Table 1 Solvent resistance test of two inorganic polymers AHPCS and PVSZ cured at either 100 or $150^{\circ} \mathrm{C}$ for $3 \mathrm{~h}$

\begin{tabular}{llllll}
\hline & AHPCS & & & PVSZ \\
\cline { 2 - 3 } \cline { 5 - 6 } \cline { 5 - 6 } & $\mathrm{N}_{2}$ cured at & $\mathrm{N}_{2}$ cured at & & $\mathrm{N}_{2}$ cured at & \multicolumn{1}{c}{$\mathrm{N}_{2}$ cured at } \\
& $100^{\circ} \mathrm{C}^{a}, 3 \mathrm{~h}$ & $160^{\circ} \mathrm{C}^{a}, 3 \mathrm{~h}$ & & $100^{\circ} \mathrm{C}^{a}, 3 \mathrm{~h}$ & $150^{\circ} \mathrm{C}^{a}, 3 \mathrm{~h}$ \\
\hline Acetone & 0.99 & 1.01 & Crack & 0.98 \\
Ethanol & 1.01 & 1.00 & 1.00 & 1.00 \\
Hexane & 1.12 & 1.02 & & 1.22 & 1.03 \\
Methanol & 1.00 & 1.00 & Crack & 1.00 \\
THF & Crack & 0.99 & Crack & Crack \\
Toluene & 1.26 & 0.99 & Crack & 0.99 \\
Acetonitrile & 1.00 & 1.00 & 1.00 & 1.00 \\
DMF & 1.00 & 1.00 & 1.00 & 1.00 \\
Water & 1.00 & 1.00 & 0.97 & 1.00
\end{tabular}

${ }^{a}$ Solvent resistances were evaluated with two inorganic polymers AHPCS and PVSZ cured at different temperatures. ${ }^{b}$ Numbers listed in this table refer to experimentally measured swelling ratio $=D / D_{\mathrm{o}}$, where $D$ and $D_{\text {o }}$ are length of cured polymer in solvent and length of dried cured polymer, respectively. low resistance to a part of the solvents used and in particular, cracking in THF. In contrast the samples cured at $160{ }^{\circ} \mathrm{C}$ for $3 \mathrm{~h}$ exhibited good stability in all solvents showing insignificant defects. This temperature effect can be attributed to the polymer's chemical structures; a higher temperature was favorable to form extensive cross-linked structure via hydrosilylation and dehydro-coupling reaction routes where active $\mathrm{Si}-\mathrm{H}$ and allyl functional groups of the AHPCS reacted with the presence of thermal initiator, dicumyl peroxide. ${ }^{14}$

Previous studies indicated that the higher dense network structure with $\mathrm{Si}-\mathrm{C}$ backbones in AHPCS can provide a stronger solvent resistance. ${ }^{15}$ The test with PVSZ samples showed similar temperature effect; PVSZ cured at a higher temperature of $150{ }^{\circ} \mathrm{C}$ for $3 \mathrm{~h}$ exhibited excellent solvent resistance against almost all the solvents used except less resistance to THF causing slight changes in sample dimensions by swelling, subject to $24 \mathrm{~h}$ soaking. This observation was in line with the previous studies on PVSZ polymers. ${ }^{6}$ Based on these test results it is suggested that both AHPCS and PVSZ can be good candidate polymers in terms of organic solvent resistance, for the fabrication of microreactors for organic chemical applications owing to the ceramic characteristics. The wettability of the cured inorganic polymer was analyzed by contact angle measurement, and the contact angle with water was noted to be around $101^{\circ}$, suggesting a highly hydrophobic nature of the surface as reported in previous work. ${ }^{6}$ It might come from the fact that both AHPCS and PVSZ have been widely used as preceramic precursors for the preparation of high temperature stable $\mathrm{SiC}$ and $\mathrm{SiCN}$ ceramic materials. ${ }^{16,17}$ It has even been claimed that the cured PVSZ polymer can act as a thermally protective coating. ${ }^{15}$ 
The optical transmittance of the two types of inorganic polymers coated on glass substrates was measured across the UV-Visible range under different curing conditions. The results are depicted in Fig. 4. The measurement from a PDMS sample is also shown for comparison. It can be seen from Fig. 4 that both cured inorganic polymers AHPCS and PSVZ showed a high transmittance (over $90 \%$ ), which is close to that of PDMS sample. ${ }^{6}$ It was observed that the AHPCS samples cured at a higher temperature $\left(160{ }^{\circ} \mathrm{C}\right)$ showed a slightly lower transmittance which was attributed to its color change from transparent to yellow tinge. Nevertheless, the optical transparence of these inorganic polymers is promising for their applications in the fabrication of microreactors, in particular when incorporating photo-induced chemistry and/or optical detections.

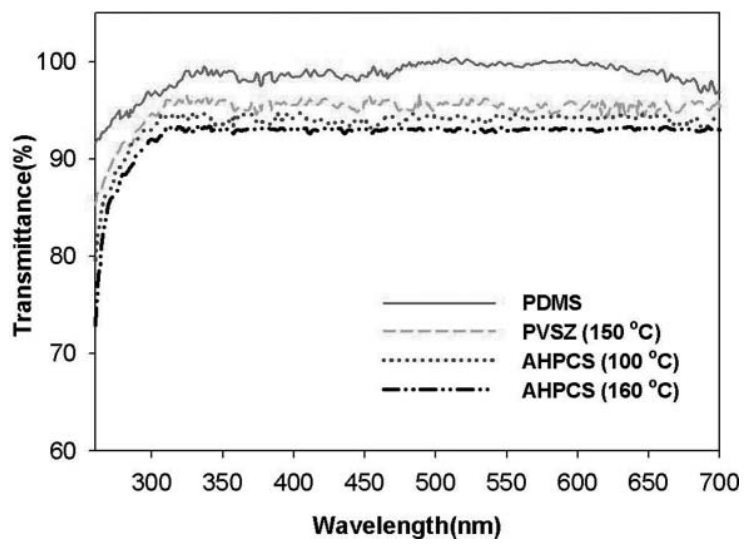

Fig. 4 Comparative UV-Vis transmittance of PDMS and inorganic polymers AHPCS and PVSZ cured at different temperatures.
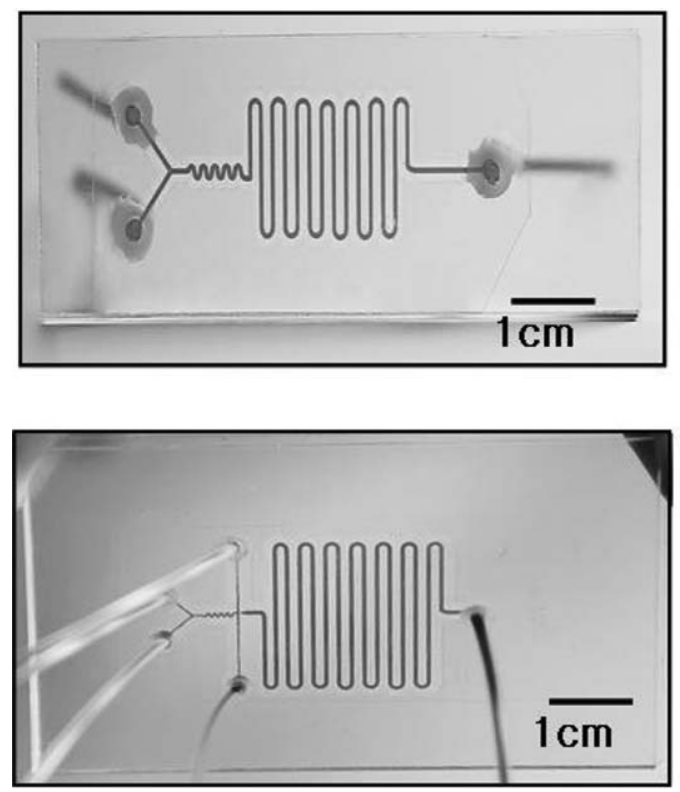

(a)
Microchemical performance of inorganic polymer microchannels

Fig. 5(a) shows the inorganic polymer derived microreactors fabricated with AHPCS and PVSZ with about $80 \%$ of production yields. It is obvious that the inorganic polymer microreactors on glass slides displayed high optical transparency where the channel layout can be clearly seen. A cross section of the the sealed microchannel, taken by SEM, is shown in Fig. 5(b) and a topographical 3D-image of the microchannel Y-junction is displayed in Fig. 5(c) showing smooth surface along the overall channel and homogenous shape with insignificant deformation from the bonding step.

In order to test the stability of the completed microreactors fabricated, various solvents were continuously pumped through the microchannels for several hours in a range of flow rates up to $10 \mu 1 \mathrm{~min}^{-1}$. It was confirmed that both types of microreactors were stable; neither leakage nor damage was observed with $4 \mathrm{~h}$ continuous flow of alcohols and acetone containing red dye to aid observation. However, THF solvent did cause partial delamination and leakage in the PVSZ based microreactor after $1 \mathrm{~h}$ running, which corresponded to the swelling observed (Table 1). On the other hand, the AHPCS based microreactor was stable as repeatedly used under all solvents given in Table 1. In addition, the chemical stability was confirmed by analysing THF solvent which was kept for $1 \mathrm{~h}$ in the AHPCS derived microchannel, using a GC-MS. It should be noted that the solvent resistance and chemical stability are remarkable in contrast to that of commonly used PDMS microchannels which can be operated only under mild aqueous conditions, including ethanol mixture for a short working period. ${ }^{18}$ These inorganic polymer reactors also showed advantages over cylic olefin copolymer (COC) based plastic microreactors which are not suitable for non-polar solvents such as hexane or toluene. ${ }^{19,20}$

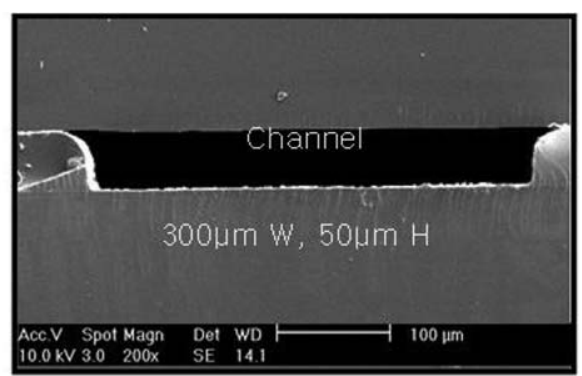

(b)

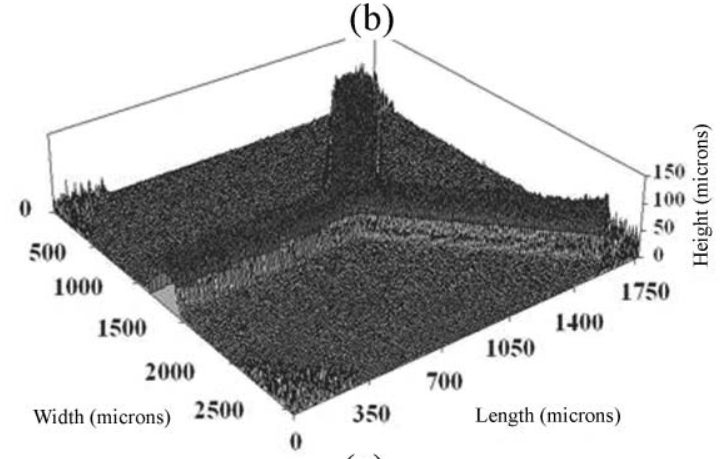

(c)

Fig. 5 (a) Image of microreactor devices fabricated with AHPCS (upper) and PVSZ (lower), (b) SEM image of the cross-section and (c) topographical image of the Y-junction using profiler. 
Table 2 Synthesis of 3,5-dimethylpirazole with AHPCS derived microreactor, glass microreactor and batch reactor

\begin{tabular}{lllll}
\hline Flow rate $/ \mu \mathrm{min}^{-1}$ & Residence time & AHPCS(\%) & Glass(\%) & Batch, \% \\
\hline 10.0 & $5.0 \mathrm{~s}$ & 13.6 & 10.2 & \\
5.0 & $10.0 \mathrm{~s}$ & 30.4 & 32.9 & \\
0.76 & $65.7 \mathrm{~s}$ & 63.6 & 59.0 & \\
& $5 \mathrm{~min}$ & & & 55.3 \\
\hline
\end{tabular}

\section{Synthesis of 3,5-dimethylpirazole}

3,5-Dimethylpirazole is a useful pharmaceutical heterocyclic intermediate in biological research, and there have been attempts to synthesize it using glass based microreactors in THF medium. ${ }^{11}$ In this study we performed this reaction within an AHPCS derived microreactor with $\mathrm{Y}$ shaped channel $(50 \mu \mathrm{m}$ deep, $500 \mu \mathrm{m}$ wide and $2 \mathrm{~cm}$ long). The reaction was also carried out in a glass based microreactor with identical channels, and in a batch system for comparison. The experimental results are summarized in Table 2. It can be seen that in both polymer and glass microreactors with continuous flow the product yield remarkably increased when the fluid residence time was increased. For example, a change in residence time within AHPCS microreator from $5.0 \mathrm{~s}$ to $65.7 \mathrm{~s}$ resulted in a yield jump from $13.6 \%$ to $63.6 \%$. This was likely due to the fact that a longer residence time allowed more time for a better mixing by diffusion of the two co-flowing reactant streams. In contrast, a noticeably longer reaction time of $300 \mathrm{~s}$ within a batch reaction vial (ID, $1 \mathrm{~cm}$; volume $1.57 \mathrm{ml}$ ), resulted in a yield of only $55.3 \%$. These results indicate that the inorganic polymer derived microreactors performances were comparable with glass made microreactors for organic synthesis at room temperature.

\section{Catalyzed Diels-Alder cycloaddition}

The Diels-Alder cycloaddition is one of the well studied in organic chemistry and has been carried out under a variety of reaction conditions within glass based reactor with both organic solvents and catalysts involved (Fig. 3(b)). In this study, the exothermic reaction was performed within a AHPCS microreactor (Y-shaped channel, $500 \mu \mathrm{m}$ wide, $50 \mu \mathrm{m}$ high and, $30 \mathrm{~mm}$ long) with THF solvent. Again the result was compared with that obtained from a batch reactor. The results are shown in Table 3. It was observed that, similar to the reaction above, the synthetic yields of product were gradually increased from 68.0 to 82.3 and $100 \%$ as the fluid residence time was extended from 12.5 to 25 and $100 \mathrm{~s}$, respectively. During repeated use
Table 3 Experimental results of Diels-Alder reaction in AHPCS derived microreactor and batch reactor

\begin{tabular}{lccc}
\hline Flow rate $/ \mu 1 \mathrm{~min}^{-1}$ & Residence time & AHPCS $(\%)$ & Batch(\%) \\
\hline 4 & $12.5 \mathrm{~s}$ & 68.0 & \\
2 & $25.0 \mathrm{~s}$ & 82.3 & \\
0.5 & $100.0 \mathrm{~s}$ & 100 & 82.0 \\
\hline
\end{tabular}

for $6 \mathrm{~h}$, the AHPCS microreactor had been preserved with no mechanical failure or chemical defections, and maintained reliable microreaction chemistry as listed in Table 3 . In contrast, the bulk batch system performed in a small size vial gave a yield of only $82.0 \%$ in spite of a much longer reaction time of $6 \mathrm{~h}$. In addition, the polymer microreactor demonstrated a good thermal performance with insignificant temperature changes during the exothermal reaction, which is attributed to the high surface-to-volume ratio enabling a fast heat dissipation from the reaction fluids to the reactor body. In contrast, a poor heat transfer in the batch reaction vessel led to a rapid heatup of the reactor up to $60^{\circ} \mathrm{C}$ without delay after the reactants were mixed. This temperature increase, in turn, affected the exothermal reaction progress resulting in a lower conversion.

\section{Knovenagel condensation}

This reaction was carried out in both PVSZ and AHPCS microreactors which had identical channel design (Fig. 3(c)) with a $160 \mathrm{~mm}$ long reaction main channel (width: $500 \mu \mathrm{m}$, depth: $50 \mu \mathrm{m}$ ). The Knovenagel condensation reaction was investigated in both microreactors under a wide variety of reaction conditions in terms of temperature, flow rate and solvent. The experimental results are summarized in Table 4 for product yields, namely 4(4-bromophenyl)-3-ethoxy-2-oxo-but-3-enenitrile.

It was found that the effect of fluid residence time (or flow rate) was similar to that observed in the two reactions described above; a longer residence time resulted in a higher yield. This applied to all the solvents used and all three temperature levels set. An increase in reaction temperature, in most cases, showed a higher yield with a given flow rate in most of the solvents used except insignificant changes in methanol solvent. It was interestingly noted that the different solvents selected had significant effects on the reaction. For example, under identical conditions (flow rate $40 \mu 1 \mathrm{~min}^{-1}$ at room temperature) in ACN a yield of $48.5 \%$ was observed whilst a more than doubled figure, $90.1 \%$, was obtained in methanol. It was found that the order of yields obtained from different kinds of solvents is as follows:

Table 4 Summarized performance of Knovenagel condensation reaction as a function of flow rate, solvent and reaction temperature

\begin{tabular}{|c|c|c|c|c|c|c|c|c|c|c|c|c|c|}
\hline \multicolumn{2}{|c|}{$\begin{array}{l}\text { Flow rate } \\
\text { (retention time) }\end{array}$} & \multicolumn{3}{|c|}{$5 \mu \mathrm{L} \mathrm{min}-1(30 \mathrm{~s})$} & \multicolumn{3}{|c|}{$10 \mu \mathrm{Lmin}^{-1}(15 \mathrm{~s})$} & \multicolumn{3}{|c|}{$20 \mu \mathrm{L} \min ^{-1}(8 \mathrm{~s})$} & \multicolumn{3}{|c|}{$40 \mu \mathrm{L} \min ^{-1}(4 \mathrm{~s})$} \\
\hline \multirow[b]{2}{*}{ Solvent } & \multirow[b]{2}{*}{ Material } & \multicolumn{3}{|c|}{ Temperature } & \multicolumn{3}{|c|}{ Temperature } & \multicolumn{3}{|c|}{ Temperature } & \multicolumn{3}{|c|}{ Temperature } \\
\hline & & RT & $40^{\circ} \mathrm{C}$ & $60{ }^{\circ} \mathrm{C}$ & RT & $40^{\circ} \mathrm{C}$ & $60^{\circ} \mathrm{C}$ & RT & $40^{\circ} \mathrm{C}$ & $60^{\circ} \mathrm{C}$ & RT & $40^{\circ} \mathrm{C}$ & $60^{\circ} \mathrm{C}$ \\
\hline Ethanol & PVSZ & 95.5 & 98.1 & 99.5 & 93.1 & 96.4 & 98.2 & 87.3 & 95.1 & 95.0 & 85.7 & 94.1 & 93.8 \\
\hline Methanol & & 96.8 & 95.6 & - & 95.3 & 94.5 & - & 91.4 & 91.4 & - & 90.1 & 90.1 & - \\
\hline DMF & & 70.5 & 77.5 & 78.5 & 63.7 & 70.8 & 72.5 & 56.0 & 63.5 & 65.4 & 51.4 & 55.8 & 60.2 \\
\hline $\mathrm{ACN}$ & & 65.0 & 66.8 & 70.4 & 61.7 & 62.3 & 65.3 & 54.2 & 58.7 & 61.2 & 48.5 & 53.3 & 56.5 \\
\hline THF & AHPCS & 89.1 & & & 86.3 & & & 85.3 & & & 80.1 & & \\
\hline
\end{tabular}


ethanol $>$ methanol $>$ THF $>$ DMF $>$ ACN. This sequence is indicative that the effect of solvent is likely due to polarity differences in different solvents. However, in order to confirm and further quantify this effect more studies need to be put forward.

After beginning the experiments, inorganic polymer chip was monitored over 8 hours to check for defects occurring from chemical instability. In the case of the PVSZ based microreactor some delamination showed under THF solvent, but the one made from AHPCS was preserved without any leakage of product and deformity of channel shape. These kinds of experiments were not reported with PDMS or plastic based microreactor but with glass microreactor. Similarly, when this reaction was carried out in a batch reactor a lower yield was obtained; a yield of $50.6 \%$ was observed in a bulk reaction vial (ID $=1 \mathrm{~cm}$, working volume $1.57 \mathrm{ml}$ ) with ethanol, despite a long reaction time of $20 \mathrm{~min}$.

\section{Conclusions}

The imprint lithography technique, which has advantages in terms of low-cost and mass production, has been employed for the fabrication of inorganic polymer-based microreactors in a cheap and simple manner. Such microreactors produced by this technique demonstrated reliable microchemical characteristics with high optical transparency, strong organic solvent resistance and stabilities for running organic synthesis reactions. Three model organic synthetic reactions, namely synthesis of 3,5dimethylpirazole, exothermic Diels-Alder cyclo-additions and Knovenagel condensation have been successfully carried out under different reaction conditions. It was demonstrated that the microchemistry performance of the inorganic polymer based microreactors was well in accordance with that of glass made microreactors, and both were significantly advantageous over batch reaction systems. These novel inorganic polymer derived microreactors proved to be promising for organic microchemistry applications.

\section{Acknowledgements}

This work was financially supported by the 2008 National Research Lab (NRL) Project [R0A20040001036702007] administered by the Korean Ministry of Science and Technology (MOST). We thank Dr Charlotte Wiles and Dr Lan-Young Hong for their kind cooperation.

\section{Notes and references}

1 X. Zhang and S. J. Haswell, MRS Bull., 2006, 31, 95.

2 D. S. Kim, S. W. Lee, T. H. Kwon and S. S. Lee, J. Micromech. Microeng., 2004, 14, 798.

3 G. Kolb and V. Hessel, Chem. Eng. J., 2004, 98, 1.

4 St. Walter, St. Malmberg, B. Schmidt and M. A. Liauw, Catal. Today, $2005,110,15$.

5 W. Ehrfeld, V. Hessel, H. Löwe, Microreactors: New Technology for Modern Chemistry, Wiley-VCH, Weinheim, Germany, 11, 2000.

6 A. Asthana, Y. Asthana, I. K. Sung and D. P. Kim, Lab Chip, 2006, 6, 1200 .

7 J. H. Park, P. A. Tuan, J. J. Lee and D. P. Kim, Polymer (Korea), 2006, 30, 407.

8 M. J. Madou, Fundamentals of microfabrication; The science of miniaturization, 2nd edn., CRC Press, 2002.

9 J. N. Lee, C. Park and G. M. Whitesides, Anal. Chem., 2003, 75, 6544.

10 I. Broadwell, P. D. I. Fletcher, S. J. Haswell, T. Mccreedy and X. L. Zhang, Lab Chip, 2001, 1, 66.

11 B. Koc, yigit Kaymakc,1oğlu and S. Rollas, Il Farmaco, 2002, 57, 595.

12 F. Fringuelli, R. Girotti, F. Pizzo and L. Vaccaro, Org. Lett., 2006, 8, 2487.

13 C. Wiles, P. Watts and S. J. Haswell, Tetrahedron, 2004, 60, 8421.

14 W. Z. Xia and W. D. Cook, Polymer, 2003, 44, 79.

15 Technical report, Clariant, http://www.clariant.com.

16 T. H. Yoon, H. J. Lee, J. Yan and D. P. Kim, J. Ceram. Soc. Jpn., 2006, 114, 473.

17 D. Klaffke, R. Wasche, N. Janakiraman and F. Aldinger, Wear, 2006, 260, 711 .

18 J. Ng. Lee, C. Park and G. M. Whitesides, Anal. Chem., 2003, 75 , 6544.

19 J. Y. Shin, J. Y. Park, C. Liu and J. S. He, Pure Appl. Chem., 2005, 77, 801.

20 Technical report, TOPAS, http://www.topas.com. 